\title{
Decontamination of Uranium-Polluted Groundwater by Chemically-Enhanced, Sawdust-Activated Carbon
}

\author{
Mahmoud O. Abd El-Magied ${ }^{1, *}$ (D), Tarek F. Mohammaden ${ }^{1}$, Ibrahim K. El-Aassy ${ }^{1}$, \\ Hamdi M. H. Gad ${ }^{2}$, Ali M. Hassan ${ }^{3}$ and Mohamed A. Mahmoud ${ }^{1}$ \\ 1 Nuclear Materials Authority, P.O. Box 530, El Maadi, Cairo 11936, Egypt; tfm20008@hotmail.com (T.F.M.); \\ IbrahimKEl-Aassy@yahoo.com (I.K.E.-A.); mam12176@yahoo.com (M.A.M.) \\ 2 Egyptian Atomic Energy Authority, Cairo 11787, Egypt; hamdigad22@gmail.com \\ 3 Chemistry Department, Faculty of Science, Al-Azhar University, Cairo 11651, Egypt; \\ alimhassanuk@yahoo.com \\ * Correspondence: mahmoud_nma@yahoo.com; Tel.: +20-10-0984-9016
}

Received: 21 September 2017; Accepted: 11 October 2017; Published: 14 October 2017

\begin{abstract}
The preparation of highly efficient and low-cost activated carbon from sawdust was achieved for the treatment of uranium-contaminated groundwater. The adsorption properties of the synthesized activated carbon, as well as their ability to be reused, were assessed. The obtained results demonstrated that sawdust activated carbon (SDAC) and its amine form (SDACA) had high affinity towards uranium ions at $\mathrm{pH}$ values of 4.5 and 5 for SDAC and SDACA, respectively. The experimental results showed that the maximum adsorption capacity of uranium was 57.34 and $76.7 \mathrm{mg} / \mathrm{g}$ for SDAC and SDACA, respectively. A maximum removal efficiency of $89.72 \%$ by SDAC and $99.55 \%$ by SDACA were obtained at a solid/liquid ratio of $8 \mathrm{mg} / \mathrm{mL}$. The removal mechanism of uranium by SDAC and SDACA was suggested due to interaction with the amine and carboxylic groups. The validation of the method was verified through uranium separation from synthetic as well as from groundwater collected from water wells in the Wadi Naseib area, Southwestern Sinai, Egypt.
\end{abstract}

Keywords: sawdust; activated carbon; uranium; groundwater; adsorption

\section{Introduction}

Freshwater resources are mainly represented by surface and groundwater bodies, and both are environmentally interrelated. Contamination of freshwater systems with thousands of industrial and chemical compounds due to the human and/or natural activities is a serious environmental problem facing humanity worldwide. In Egypt, the groundwater is the major source of domestic water for people living in rural and semi-urban areas for geological reasons in some localities; the groundwater may be contaminated with radioactive and toxic elements that impose negative health effects, particularly on prolonged exposure [1-3]. The uranium concentration in the groundwater depends on the lithology, geomorphology and other geological conditions of the region around the water wells. Assessment of the risk of impact from uranium is based on the chemical toxicity and radiological toxicity. Uranium is known to cause acute toxicological effects and harmful diseases for human such as lung, pancreatic, bone and liver cancer [4]. The chemistry of uranium in aqueous solutions is governed by the dioxocation $\mathrm{UO}_{2}{ }^{2+}[\mathrm{O}=\mathrm{U}=\mathrm{O}]^{2+}$. In aqueous solutions various oligomeric and monomeric hydrolyzed species of $\mathrm{U}(\mathrm{VI})$ have been reported such as $\left[\mathrm{UO}_{2} \mathrm{OH}\right]^{+},\left[\left(\mathrm{UO}_{2}\right)_{3}(\mathrm{OH})_{4}\right]^{2+}$, $\left[\left(\mathrm{UO}_{2}\right)_{3}(\mathrm{OH})_{5}\right]^{+},\left[\left(\mathrm{UO}_{2}\right)_{2}(\mathrm{OH})_{2}\right]^{2+},\left[\left(\mathrm{UO}_{2}\right)_{2} \mathrm{OH}\right]^{3+},\left[\left(\mathrm{UO}_{2}\right)_{3}(\mathrm{OH})\right]^{5+},\left[\left(\mathrm{UO}_{2}\right)_{4}(\mathrm{OH})\right]^{7+},\left[\mathrm{UO}_{2}(\mathrm{OH})_{4}\right]^{2-}$ and $\left[\left(\mathrm{UO}_{2}\right)_{3}(\mathrm{OH})_{7}\right]^{-}$. In the presence of carbonate anions, monomeric and oligomeric carbonate species such as $\left[\mathrm{UO}_{2} \mathrm{CO}_{3}\right],\left[\mathrm{UO}_{2}\left(\mathrm{CO}_{3}\right)_{2}\right]^{2-}$, $\left[\mathrm{UO}_{2}\left(\mathrm{CO}_{3}\right)_{3}\right]^{4-}$ and $\left[\left(\mathrm{UO}_{2}\right)_{3}\left(\mathrm{CO}_{3}\right)_{6}\right]^{6-}$ may also be formed with different concentrations depending on the $\mathrm{pH}$ and the total concentration of $\mathrm{U}(\mathrm{VI})$ [5-7]. 
Several techniques are used for removal of uranium and trace metals from water, e.g., biotechnology (including agricultural wastes), solvent extraction, coagulation, reduction, ion exchange, reverse osmosis, flocculation, electrochemical and adsorption [8-13]. However, most of these techniques have some difficulties such as incomplete metal removal (poor efficiency), high reagent and energy requirements, and large quantities of resulting wastes that are difficult to dispose of, as well as the generation of toxic waste products. In addition, uranium-carbonate anion species cannot be adsorbed on some adsorbents like iron oxides [8,9]. Other techniques (such as membrane separation) are quite effective, but are not feasible for the decontamination of huge amounts of polluted agues medium or for the remediation of large contaminated areas because of their high cost.

The adsorption of uranium and heavy metals from the groundwater has been found to be a superior technique compared to other methods because it is a simple, effective, economical, and environmental technique [7]. Activated carbon (AC) is one of the most widely used adsorbents in environmental applications. Activated carbon is a family member of carbons including carbon blacks, nuclear graphite, carbon fibers, composites, electrode graphite, and more. Any cheap material with a high carbon content and low inorganic can be used as a raw material for the production of activated carbon [14-24].

The characteristics of activated carbon as a highly efficient and low-cost adsorbent motivated the current work, where the authors tested the sawdust activated carbon and its modified form (amino-activated carbon) as efficient adsorbents for the removal of uranium ions from aqueous solution (including a synthetic solution and real contaminated groundwater). Batch studies were conducted and the parameters of uranium initial concentration, $\mathrm{pH}$ and contact time were studied to achieve the optimum conditions.

\section{Experiment}

\subsection{Chemicals and Apparatus}

Analytical grade chemical reagents were used for preparing the working solutions in this study. All solutions of different uranium concentrations were derived from a stock solution of $1000 \mathrm{ppm}$ $\mathrm{U}(\mathrm{VI})$, which was prepared by dissolving $1.782 \mathrm{~g}$ of uranium nitrate hexahydrate $\left[\mathrm{UO}_{2}\left(\mathrm{NO}_{3}\right)_{2} \cdot 6 \mathrm{H}_{2} \mathrm{O}\right]$ in $1000 \mathrm{~mL}$ of de-ionized water. The $\mathrm{pH}$ measurements were carried out using a digital $\mathrm{pH}$ meter (model Digimed DM-21, Digimed, São Paulo, SP, Brazil).

The pollutant was determined using a UV/Vis spectrophotometer (model Unicam UV2-100, Unicam Ltd., Cambridge, UK). Other elements were measured by atomic absorption spectrometer (model Unicam 969, Unicam Ltd., Cambridge, UK). All the activated carbon samples were prepared in the Analytical Chemistry and Environmental Control Department, Hot Laboratories and Waste Management Center, Egyptian Atomic Energy Authority. Modification of the activated carbon and the controlling factors were carried out by the Egyptian Nuclear Materials Authority.

\subsection{Preparation and Modification of Adsorbents}

Steam-activated carbon from sawdust was prepared by heating $30 \mathrm{~g}$ of clean, dry sawdust to the specified temperature in a tube furnace with an inclination angle $70^{\circ}$ to allow the pyrolysis products to flow. The temperature was raised gradually $\left(50{ }^{\circ} \mathrm{C} / 10 \mathrm{~min}\right.$.) to allow the free evolution of volatiles, up to $350{ }^{\circ} \mathrm{C}$ under a limited amount of air. Pure steam was then introduced through the heated mass with a continuous temperature rising up to $750{ }^{\circ} \mathrm{C}$. The product was soaked at this temperature for $2 \mathrm{~h}$, in the presence of steam. Finally, the product SDAC was cooled to room temperature.

A known weight of SDAC was soaked in hydrochloric acid solutions (1:1) for $24 \mathrm{~h}$ at room temperature to remove the metal ions and other impurities. After the completion of the reaction, the formed beads were decanted, washed and dried. The purified SDAC adsorbent was oxidized with $100 \mathrm{~mL} 5 \mathrm{M} \mathrm{HNO}_{3}$ solution for $6 \mathrm{~h}$ with stirring at $75^{\circ} \mathrm{C}$. The oxidized SDAC was filtered and washed with the de-ionized water until aqueous $\mathrm{pH} 7$ was obtained. Then, the product was repeatedly washed 
with ethanol, and dried. Ten grams of SDAC was reacted with $40 \mathrm{~mL}$ of Tetraethylenepentamine (TEPA) in $40 \mathrm{~mL}$ of toluene and stirred at $80^{\circ} \mathrm{C}$ for $8 \mathrm{~h}$. The product (amino form, SDACA) was washed with ethanol until complete removal of the non-reacted chemicals and then was dried in a drying oven at $105^{\circ} \mathrm{C}$ for approximately $6 \mathrm{~h}$.

The surface features of the activated carbon samples were identified using a scanning electronic microscope with an energy dispersive X-ray spectrometer (SEM/EDX, XL 30 ESEM, Philips Co., Amsterdam, The Netherlands). FTIR (Perkin-Elmer FTIR-1600, PerkinElmer, Waltham, MA, USA) recorded the infrared spectra of prepared materials.

\subsection{Adsorption Measurements Using the Batch Method}

To study the factors that affected the adsorption process, batch experiments were carried out by shaking conical flasks containing the desired dose of adsorbent (varied from 10 to $200 \mathrm{mg}$ ) in a predetermined concentration of $\mathrm{U}(\mathrm{VI})$ solution at a $\mathrm{pH}$ range of $1-7$ during a certain time and at a different temperature. After attaining the equilibrium, the filtrates were analyzed to determine the concentration of the remaining $\mathrm{U}(\mathrm{VI})$ ions. The adsorption capacity, $\mathrm{q}_{\mathrm{e}}(\mathrm{mg} / \mathrm{g})$ and percent of uranium removal from the solution, removal $(\%)$, were calculated by the following equations $[25,26]$.

$$
\begin{gathered}
\mathrm{q}_{\mathrm{e}}=\frac{\left(\mathrm{C}_{\mathrm{i}}-\mathrm{C}_{\mathrm{e}}\right) \mathrm{V}}{\mathrm{Wt}} \\
\text { Removal \% }=\frac{\left(\mathrm{C}_{\mathrm{i}}-\mathrm{C}_{\mathrm{e}}\right)}{\mathrm{C}_{\mathrm{e}}} \times 100
\end{gathered}
$$

where $C_{i}$ is the initial uranium ion concentration $(\mathrm{mg} / \mathrm{L}) ; \mathrm{C}_{\mathrm{e}}$ is the final uranium ion concentration at equilibrium (mg/L); $\mathrm{V}$ is the volume (L); and $\mathrm{Wt}$ is the weight of the adsorbent (g). Additionally, different kinetics, isotherms, and thermodynamic parameters were calculated.

\section{Results and Discussion}

\subsection{Adsorbent Structure and Characterization}

Synthesis of activated carbon from the sawdust SDAC and its modified form SDACA was illustrated in Scheme 1. The FTIR spectrum of SDAC, Figure 1, shows the characteristic peaks of $\mathrm{OH}$ $\left(3426 \mathrm{~cm}^{-1}\right), \mathrm{CH}_{2}\left(2358 \mathrm{~cm}^{-1}\right), \mathrm{CO}\left(1626 \mathrm{~cm}^{-1}\right)$ and $\mathrm{CH}\left(878 \mathrm{~cm}^{-1}\right)$ groups. After functionalization with TEPA, the characteristic peaks of $\mathrm{OH}\left(3424 \mathrm{~cm}^{-1}\right), \mathrm{CH}_{2}\left(2369 \mathrm{~cm}^{-1}\right), \mathrm{NH}_{2}\left(2093 \mathrm{~cm}^{-1}\right), \mathrm{NH}$ $\left(1564 \mathrm{~cm}^{-1}\right)$ and $\mathrm{CN}\left(1179 \mathrm{~cm}^{-1}\right)$ groups were observed, which means the successful grafting of an amino group onto SDAC. The infrared spectrum of SDAC and SDACA showed shifts in the characteristic bands of $(\mathrm{C}=\mathrm{C}),(\mathrm{O}-\mathrm{H}),\left(\mathrm{NH}_{2}\right),(\mathrm{C}=\mathrm{C})$ and $(\mathrm{C}-\mathrm{C})$ to a lower or higher value compared to the spectrum of the uranium-loaded SDAC and SDACA adsorbents. Changes in the peak intensity indicates that U-binding has taken place on the surface of the activated carbon $[7,21]$.

The SEM images, Figure 1, illustrate the surface features of SDAC and SDACA before and after uranium adsorption. Also, the EDX charts, Figure 1, show the elemental composition of SDAC and SDAC after contact with the uranium ions, proving that SDACA retained a high amount of uranium ions on the adsorbents. 


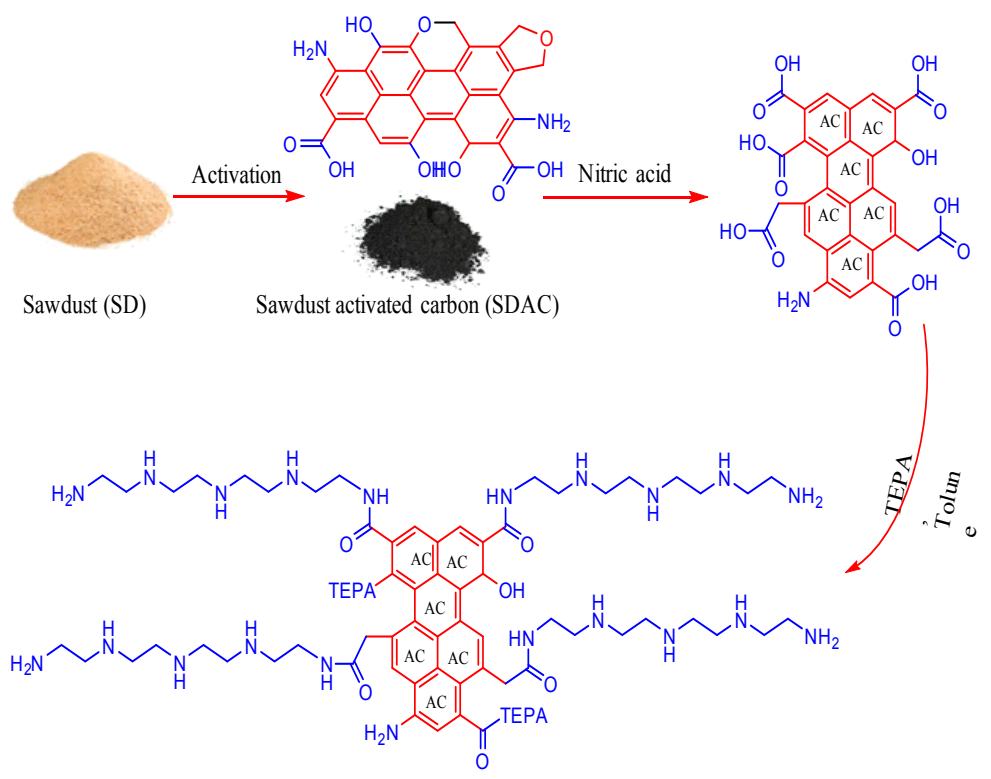

Sawdust activated carbon/TEPE (SDACA)

Scheme 1. The synthesis and modification of sawdust activated carbon.
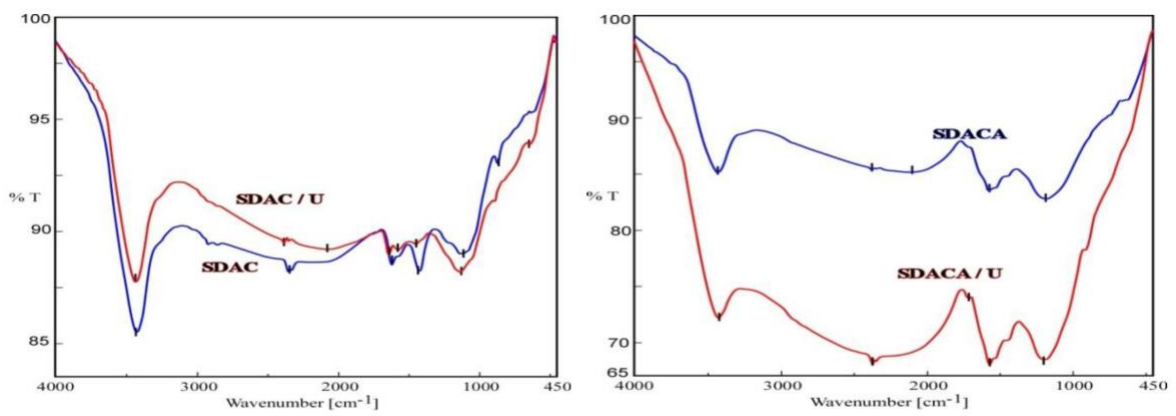

(A)
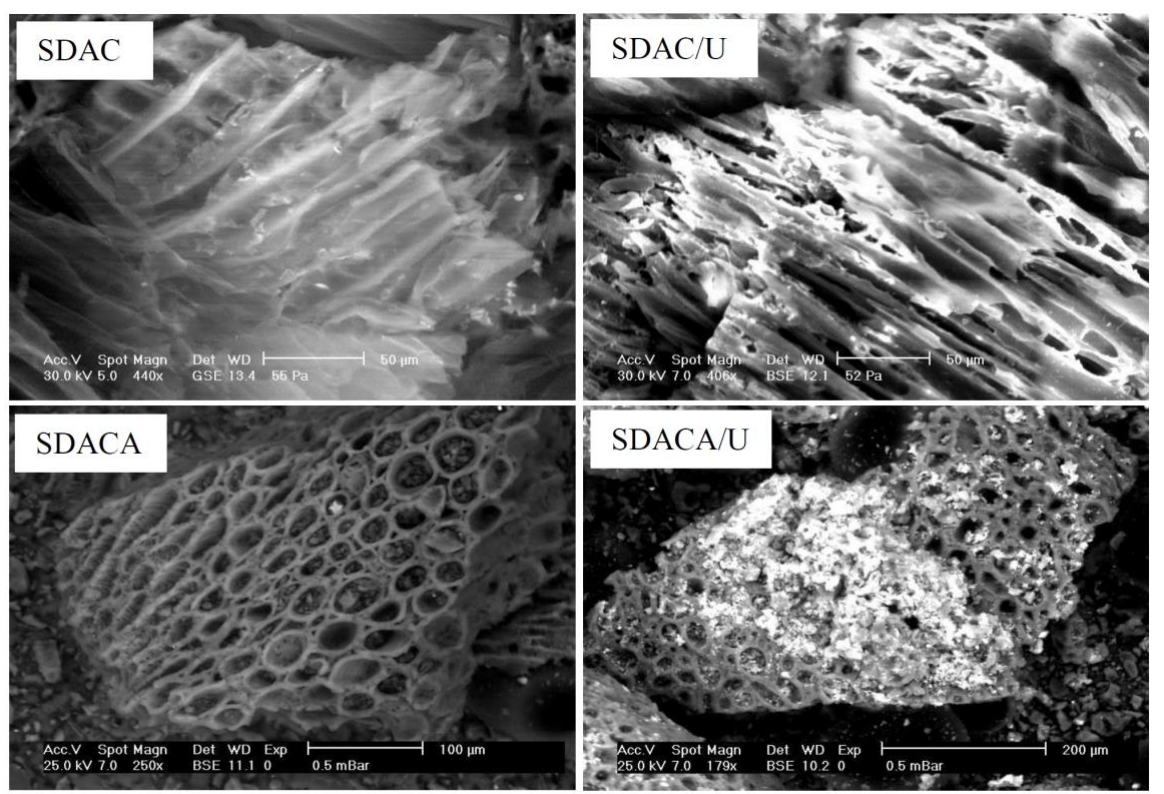

(B)

Figure 1. Cont. 

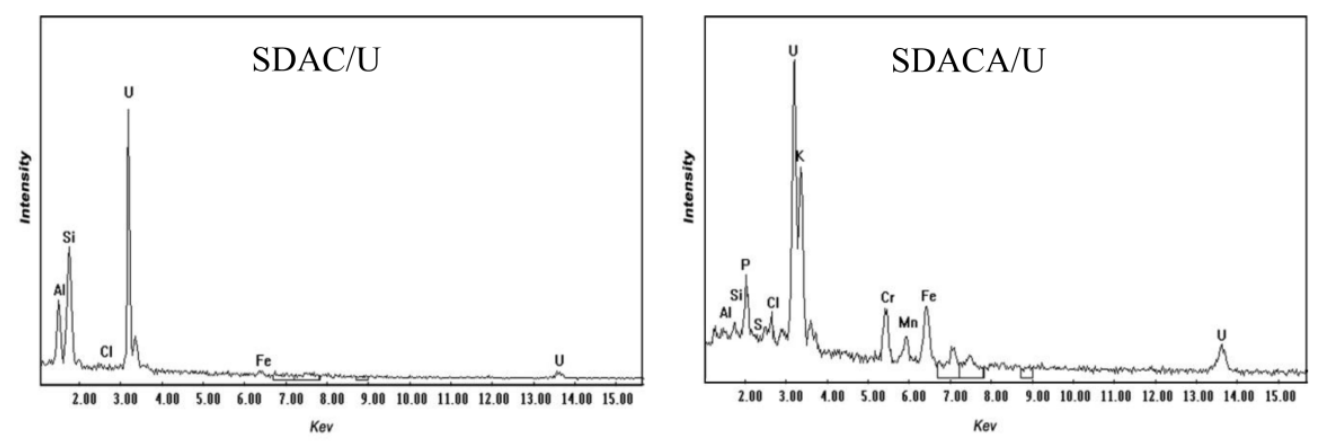

(C)

Figure 1. FTIR (A), SEM (B) and EDX (C) images of the studied materials.

\subsection{Effect of $p H$ on $U(V I)$ Ion Adsorption}

Uranium ion adsorption by both SDAC and SDACA was tested under gradual $\mathrm{pH}$ values (1-6), Figure 2, to verify the $\mathrm{pH}$ role in the adsorption process. It is clear that the $\mathrm{U}(\mathrm{VI})$ adsorption by the two adsorbents increased as the $\mathrm{pH}$ increased, when the maximum adsorption was 57.34 and 76.7 at $\mathrm{pH} 4.5$ and 5 for SDAC and SDACA, respectively.

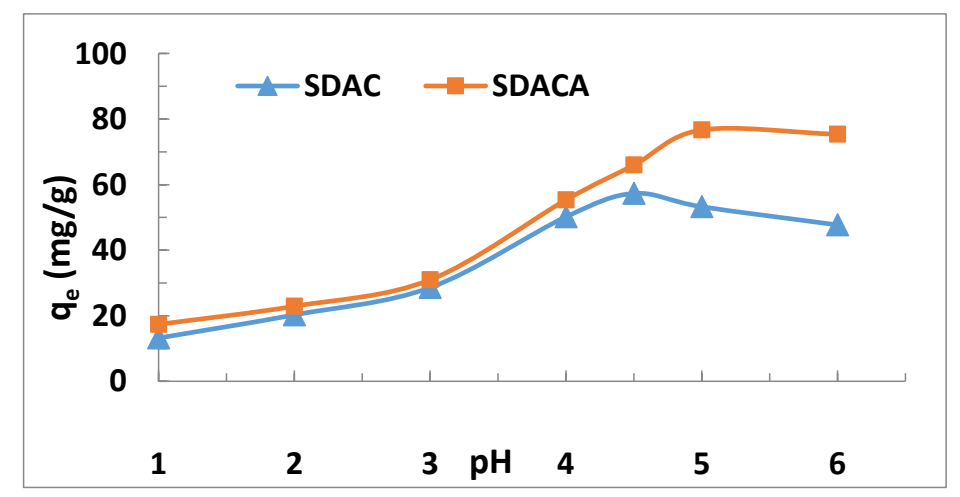

(A)
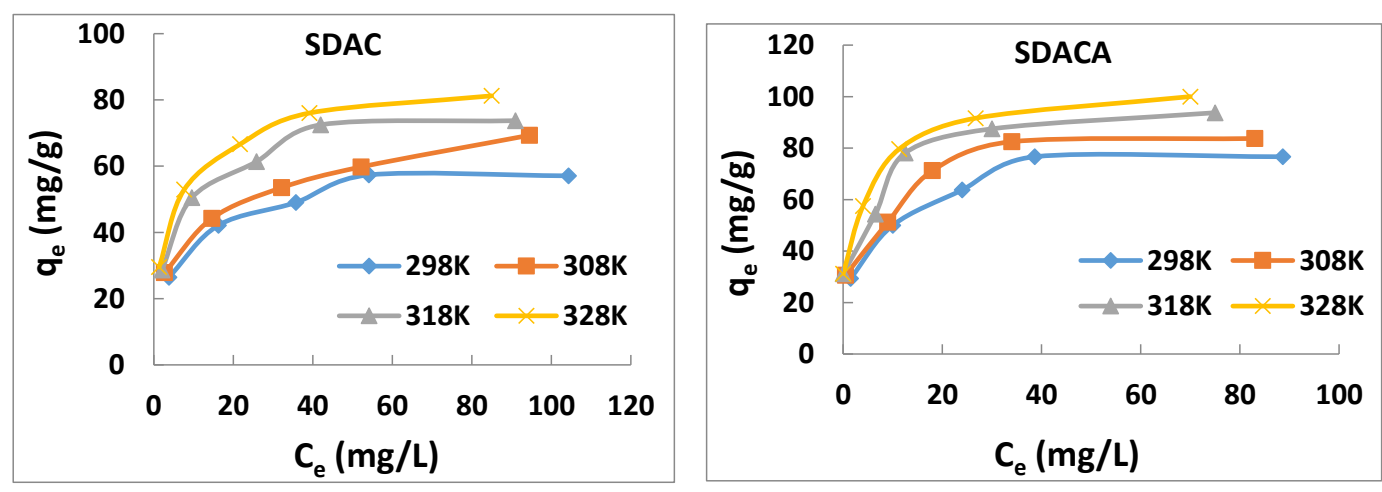

(B)

Figure 2. Effect of $\mathrm{pH}(\mathbf{A})$ and $\mathrm{U}(\mathrm{VI})$ concentration on adsorption process $(\mathbf{B})$.

The low $\mathrm{U}(\mathrm{VI})$ adsorption with lower $\mathrm{pH}$ values was reasonably attributed to the protonation of the effective functional groups $\left(\mathrm{NH}_{2}\right.$ and $\left.\mathrm{COOH}\right)$ on the two adsorbents, hence no electron density can 
be donated to the uranyl cations $[27,28]$. On the other hand, further increases in the $\mathrm{pH}$ above five caused precipitation of the uranium hydroxide, which was accompanied by a decrease of uranium adsorption. The suggested mode of interaction between the uranium ions and the activated carbon (Scheme 2) is as follows:

$$
\begin{aligned}
& \text { AC.COOH }+\mathrm{UO}_{2}^{2+} \rightarrow(\text { AC.COO })_{2} \mathrm{UO}_{2}+2 \mathrm{H}^{+} \\
& \mathrm{AC} . \mathrm{COOH}+\mathrm{UO}_{2}^{2+} \rightarrow[\mathrm{AC} . \mathrm{COOHUO}]^{2+} \\
& \text { AC. } \mathrm{NH}_{2}+\mathrm{UO}_{2}^{2+} \rightarrow\left[\text { AC. } \mathrm{NH}_{2} \mathrm{UO}_{2}\right]^{2+}
\end{aligned}
$$

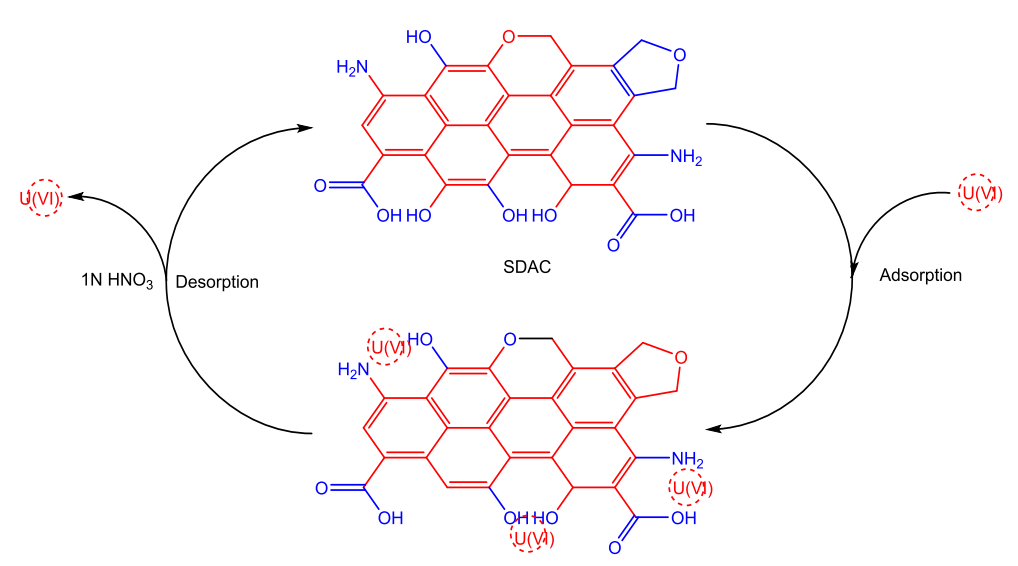

(A)

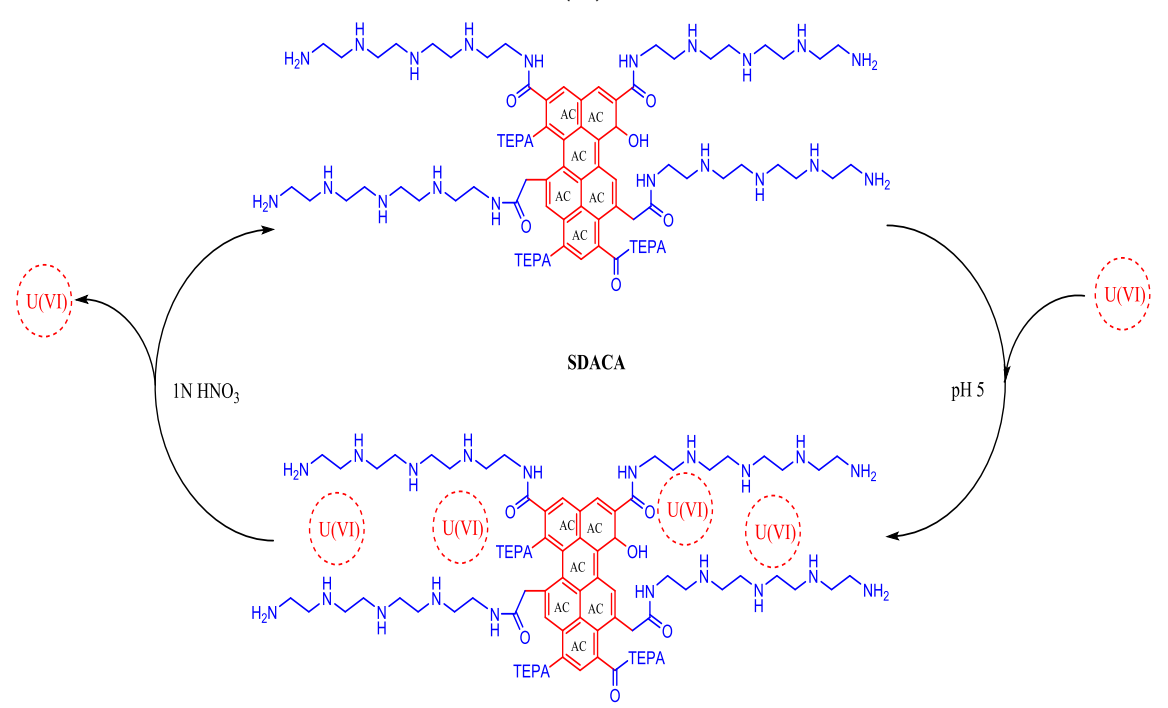

(B)

Scheme 2. The suggested mechanism of interaction of $\mathrm{U}(\mathrm{VI})$ by sawdust activated carbon, SDAC (A) and its amine form SDACA (B).

\subsection{Effect of Initial U(VI) Ion Concentration}

Figure 2 shows the relation between the initial uranium concentration and the adsorption process at $25^{\circ} \mathrm{C}$. Figure 2 showed a mutual increase in both the adsorbents until reaching a plateau, at which the maximum uptake value for SDAC and SDACA were 57.34 and $76.7 \mathrm{mg} / \mathrm{g}$, respectively. This may be explained by a decrease in the resistance to mass transfer from the aqueous phase to the sorbents solid phase, therefore, the adsorption increases at higher metal concentrations. 


\subsection{Effect of Temperature}

The effect of operating temperature variations $\left(25-55^{\circ} \mathrm{C}\right)$ on the uranium sorption was studied (Figure 2). The results revealed a relative increase in the sorption percentage with an increase in temperature. Increasing the temperature caused an increase in the rate of diffusion of the metal ions across the external boundary layer and in the internal pores of the SDAC and SDACA beads. Clearly, higher temperatures increased the mobility of the solute, which enhanced the penetration of molecules inside the pores of the adsorbent, hence resulting in a larger uptake capacity.

\subsection{Adsorption Isotherms}

Adsorption equilibrium was carried out for uranium ion concentrations varying from 25 to $150 \mathrm{ppm}$. The obtained experimental data were tested with the linearized form of Langmuir, Freundlich, Dubinin-Radushkevich, and Temkin isotherms models at the constant of nickel $\mathrm{pH}$, temperature, contact time and adsorbent dosage.

\subsubsection{Langmuir Isotherms}

The Langmuir isotherm model is based on the several assumptions, such as that the sorption energy is constant, all sorption sites are equivalent and the adsorbent surface is homogenous. It also states that the maximum sorption responds to a saturated monolayer of metal ions on the adsorbent surface, that there is no transmigration of the adsorbate in the adsorbent surface, and that sorption in an active site is independent of whether the adjacent sites are occupied or not [26-28]. The adsorption isotherms, obtained at $25,35,45$ and $55^{\circ} \mathrm{C}$, were plotted according to the Langmuir model (Equation (6)), and the data obtained are provided in Figure 3.

$$
\frac{\mathrm{C}_{\mathrm{e}}}{\mathrm{q}_{\mathrm{e}}}=\frac{\mathrm{C}_{\mathrm{e}}}{\mathrm{Q}_{\text {Lan }}}+\frac{1}{\mathrm{~K}_{\mathrm{L}} \mathrm{Q}_{\text {Lan }}}
$$

where $\mathrm{Q}_{\text {Lan }}$ is the Langmuir maximum adsorption capacity $(\mathrm{mg} / \mathrm{g})$, and $\mathrm{K}_{\mathrm{Lan}}$ is the Langmuir binding constant. The plots of $\mathrm{C}_{\mathrm{e}}$ / cue versus $\mathrm{C}_{\mathrm{e}}$ show high correlation coefficients, indicating that the sorption of uranium obeys the Langmuir isotherm model. In addition, the calculated maximum sorption capacities corresponding to complete monolayer sorption at different temperatures are in agreement with those obtained from the experimental data. Table 1 shows that the values of $Q_{L a n}$ and $K_{L}$, which are, respectively, related to the maximum sorption capacity and the energy of sorption, increase when the temperature increases. This can be attributed to the endothermic nature of the sorption process. The observed increase in the value of $\mathrm{K}_{\mathrm{L}}$ may be attributed to the increase of the activated carbon/uranium interaction. The Langmuir binding constant $\left(\mathrm{K}_{\mathrm{Lan}}\right)$ may be used to estimate the practical degree of suitability of the adsorbents. The suitability of the Langmuir isotherm model for describing the sorption of uranium ions onto the SDAC and SDACA surface can be attributed to the homogenous distribution of uranium ions, or chelating sites, on the SDAC and SDACA surface [7].

The separation factor, $\mathrm{R}_{\mathrm{L}}$, (Equation (7)) can be used to predict whether a sorption system is favorable or unfavorable. This parameter results from the essential characteristics of the Langmuir equation and can be calculated by

$$
\text { Separation factor constant }=\frac{1}{1+\mathrm{K}_{\mathrm{L}} \mathrm{C}_{\circ}}
$$

The obtained data clearly show that in all the cases, the values of $R_{L}$ were positive and less than unity $(0.04-0.22)$, indicating thereby a highly favorable sorption process for uranium ions under the conditions used in this study. 

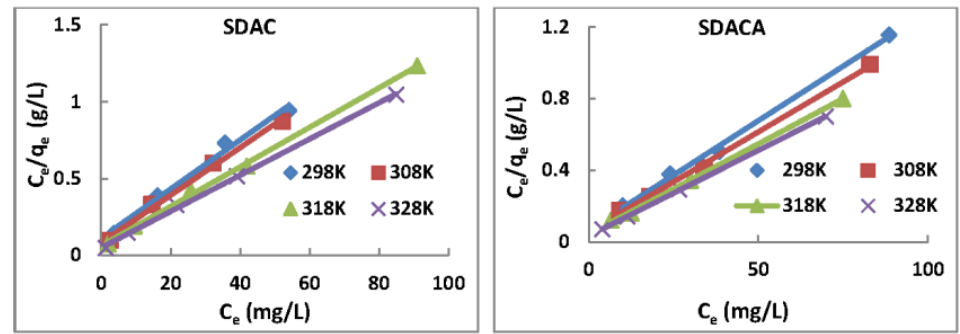

(A)
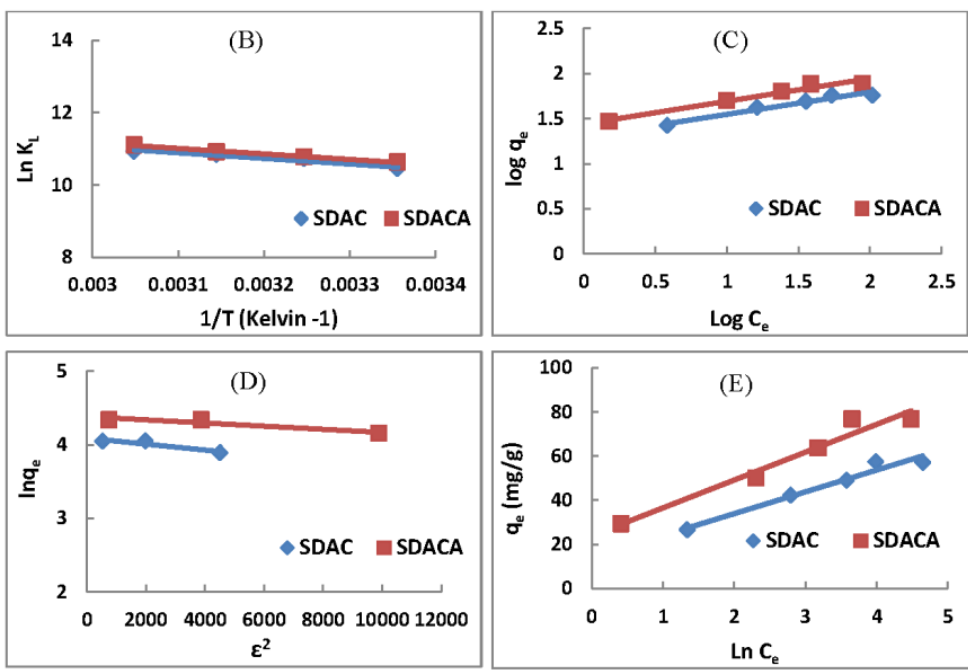

Figure 3. Langmuir (A), Van't Hoff (B), Freundlich (C), Dubinin-Radushkevich (D) and Temkin's (E) isotherm models for $\mathrm{U}(\mathrm{VI})$ adsorption onto SDAC and SDACA adsorbents.

Table 1. Adsorption isotherms of U(VI) ions by SDAC and SDACA.

\begin{tabular}{|c|c|c|c|c|}
\hline $\begin{array}{l}\text { Isotherms } \\
\text { Model }\end{array}$ & Parameters & (SDAC) & (SDACA) & Temperature \\
\hline \multirow{9}{*}{$\begin{array}{l}\text { Langmuir } \\
\text { isotherm }\end{array}$} & \multirow{4}{*}{$\mathrm{q}_{\max },(\mathrm{mg} / \mathrm{g})$} & 62.50 & 82.645 & $298 \mathrm{~K}$ \\
\hline & & 64.516 & 89.286 & $308 \mathrm{~K}$ \\
\hline & & 77.519 & 99.0099 & $318 \mathrm{~K}$ \\
\hline & & 84.746 & 105.263 & $328 \mathrm{~K}$ \\
\hline & \multirow{4}{*}{$\mathrm{K}_{\mathrm{L}},(\mathrm{L} / \mathrm{mg})$} & 0.144 & 0.175 & $298 \mathrm{~K}$ \\
\hline & & 0.191 & 0.20 & $308 \mathrm{~K}$ \\
\hline & & 0.214 & 0.231 & $318 \mathrm{~K}$ \\
\hline & & 0.225 & 0.281 & $328 \mathrm{~K}$ \\
\hline & $\mathrm{R}^{2}$ & 0.989 & 0.9969 & $298 \mathrm{~K}$ \\
\hline \multirow{3}{*}{$\begin{array}{l}\text { Freundlich } \\
\text { isotherm }\end{array}$} & $\mathrm{K}_{\mathrm{F}},(\mathrm{mg} / \mathrm{g})$ & 20.091 & 27.568 & \multirow{3}{*}{$298 \mathrm{~K}$} \\
\hline & N & 4.085 & 3.957 & \\
\hline & $\mathrm{R}^{2}$ & 0.9503 & 0.9612 & \\
\hline \multirow{4}{*}{$D-R$ isotherm } & $\mathrm{q}_{\max },(\mathrm{mg} / \mathrm{g})$ & 59.806 & 80.0698 & \multirow{4}{*}{$298 \mathrm{~K}$} \\
\hline & $\mathrm{K}_{\mathrm{ad}},\left(\mathrm{mol}^{2} / \mathrm{kJ}^{2}\right)$ & $4.00 \times 10^{-8}$ & $2.00 \times 10^{-8}$ & \\
\hline & $\mathrm{E},(\mathrm{kJ} / \mathrm{mol})$ & 3.536 & 5.00 & \\
\hline & $\mathrm{R}^{2}$ & 0.8513 & 0.8868 & \\
\hline \multirow{4}{*}{$\begin{array}{l}\text { Temkin } \\
\text { isotherm }\end{array}$} & $\beta(\mathrm{kJ} / \mathrm{mol})$ & 9.877 & 12.60 & \multirow{4}{*}{$298 \mathrm{~K}$} \\
\hline & $\mathrm{A}_{\mathrm{T}}(\mathrm{L} / \mathrm{g})$ & 4.177 & 6.690 & \\
\hline & B & 250.838 & 196.586 & \\
\hline & $\mathrm{R}^{2}$ & 0.9628 & 0.9577 & \\
\hline
\end{tabular}


Evaluation of the thermodynamic parameters was used to assess the spontaneity of the sorption process (Equations (8) and (9)).

$$
\begin{aligned}
\ln \mathrm{K}_{\mathrm{L}} & =\frac{\Delta \mathrm{S}^{\mathrm{o}}}{\mathrm{R}}-\frac{\Delta \mathrm{H}^{\mathrm{o}}}{\mathrm{RT}} \\
\Delta \mathrm{G}^{\mathrm{o}} & =\Delta \mathrm{H}^{\mathrm{o}}-\mathrm{T} \Delta S^{\mathrm{o}}
\end{aligned}
$$

where $\mathrm{R}$ is the universal gas constant $\left(8.314 \mathrm{~J} \mathrm{~mol}^{-1} \mathrm{~K}^{-1}\right)$; $\mathrm{T}$ is the absolute temperature $(\mathrm{K})$; enthalpy change $\left(\Delta \mathrm{H}^{\circ}\right)$; entropy change $\left(\Delta \mathrm{S}^{\circ}\right)$; and Gibbs free energy $\left(\Delta \mathrm{G}^{\circ}\right)$. The values of $\mathrm{K}_{\mathrm{L}}$ at the different temperatures were used to calculate the thermodynamic parameters for the sorption of $\mathrm{U}(\mathrm{VI})$ ions onto SDAC and SDACA (Figure 3). The calculated thermodynamic parameters (enthalpy change $\left(\Delta \mathrm{H}^{\circ}\right)$ and entropy change $\left(\Delta S^{\circ}\right)$, and Gibbs free energy $\left(\Delta G^{\circ}\right)$ ) for the sorption of $\mathrm{U}(\mathrm{VI})$ ions onto SDAC and SDACA are reported in Table 2.

\begin{tabular}{|c|c|c|c|c|c|}
\hline \multirow[b]{2}{*}{ Adsorbents } & \multirow[b]{2}{*}{ Temp. (Kelvin) } & \multicolumn{4}{|c|}{ Thermodynamic Parameters } \\
\hline & & $\Delta \mathrm{H}^{\circ}(\mathrm{kJ} / \mathrm{mol})$ & $\begin{array}{c}\Delta \mathrm{S}^{\circ} \\
(\mathrm{KJ} /(\mathrm{mol} \cdot \mathrm{K}))\end{array}$ & $\mathrm{T} \Delta \mathrm{S}^{\circ}(\mathrm{kJ} / \mathrm{mol})$ & $\Delta \mathrm{G}^{\circ}(\mathrm{kJ} / \mathrm{mol})$ \\
\hline \multirow{4}{*}{ SDAC } & 298 & \multirow{4}{*}{12.93} & \multirow{4}{*}{0.131} & 38.93 & -5.99 \\
\hline & 308 & & & 40.23 & -27.30 \\
\hline & 318 & & & 41.54 & -28.61 \\
\hline & 328 & & & 42.84 & -29.91 \\
\hline \multirow{4}{*}{ SDACA } & 298 & \multirow{4}{*}{12.73} & \multirow{4}{*}{0.131} & 304 & -26.31 \\
\hline & 308 & & & 40.35 & -27.62 \\
\hline & 318 & & & 41.66 & -28.93 \\
\hline & 328 & & & 42.97 & -30.24 \\
\hline
\end{tabular}

Table 2. Thermodynamic parameters for the adsorption of U(VI) by SDAC and SDACA.

The negative values of $\Delta \mathrm{G}^{\circ}$ are due to the high affinity of uranium to SDAC and SDACA and the spontaneous nature of the sorption process for uranium ions. However, the $\Delta \mathrm{G}^{\circ}$ value becomes more and more negative with the increase in temperature, indicating that the extent of spontaneity is proportional to the temperature and, therefore, higher temperature favors the sorption process for metal ions. The positive value of $\Delta \mathrm{H}^{\circ}$ shows the endothermic nature of the adsorption process, confirming that the intensity of the sorption process is enhanced at higher temperatures [26-28]. The positive value of $\Delta S^{\circ}$ confirms the affinity of the sorbent for uranium ions and suggests the increased randomness at the solid/solution interface during the sorption process. The positive value of $\Delta \mathrm{S}^{\circ}$ may be related to the liberation of water hydration during the adsorption process causing the increase in the randomness of the system. The $\Delta G^{\circ}$ values confirm the spontaneous nature and feasibility of the sorption process and the favorable $\mathrm{U}(\mathrm{VI})$ sorption takes place with increasing temperature.

\subsubsection{Freundlich Model}

The Freundlich isotherm is the earliest known relationship and assumes that the sorption process is non-ideal, reversible and multilayer [7]. Equation (13) gives the linear form of the Freundlich model. The adsorption data of $\mathrm{U}(\mathrm{VI})$ ions at $25^{\circ} \mathrm{C}$ were tested according to the Freundlich model and the values of the Freundlich parameters were calculated and illustrated in (Table 1).

$$
\log \mathrm{q}_{\mathrm{e}}=\log \mathrm{K}_{\mathrm{F}}+\frac{1}{\mathrm{n}} \log \mathrm{C}_{\mathrm{e}}
$$

where $\mathrm{K}_{\mathrm{F}}$ and $1 / \mathrm{n}$ are constants related to theoretical adsorption capacity and intensity of adsorbent/adsorbate binding, respectively. The Freundlich plots, Figure 3, gave a slope less than one, indicating nonlinear adsorption behavior with the concentration of $\mathrm{U}(\mathrm{VI})$ in the concentration range studied. There is a difference between the theoretical adsorption capacities from Freundlich and the 
experimental ones indicating the non-applicability of Freundlich to the studied adsorption process (Table 1).

\subsubsection{Dubinin-Radushkevich Isotherms}

The Dubinin-Radushkevich isotherm model was tested with the adsorption data to estimate the energy of adsorption to the nature of the adsorption process as physisorption or chemisorption. The linear form of this model (Equations (11)-(13)) is more general than the Langmuir model because it considers a heterogeneous surface $[27,28]$.

$$
\begin{gathered}
\ln \mathrm{q}_{\mathrm{e}}=\ln \mathrm{Q}_{\mathrm{D}}-\beta \varepsilon^{2} \\
\varepsilon=\mathrm{RT} \ln \left(1+\frac{1}{\mathrm{C}_{\mathrm{e}}}\right) \\
\mathrm{E}=\frac{1}{\sqrt{2 \beta}}
\end{gathered}
$$

where $Q_{D}$ is the maximum adsorption capacity $(\mathrm{mg} / \mathrm{g})$ and $\beta$ is a constant related to adsorption mean free energy; $\varepsilon$ is Polanyi potential; and $\mathrm{E}(\mathrm{kJ} / \mathrm{mol})$ is the adsorption mean free energy, which can be obtained using the following equation. Plotting (ln $\mathrm{q}_{\mathrm{e}}$ ) against $\varepsilon^{2}$, (Figure 3), gives a straight line with slope and intercepts equal to $\beta$ and $\ln Q_{D}$, respectively. The calculated value of adsorption mean free energy was found to be 3.5 and $5 \mathrm{~kJ} / \mathrm{mol}$ for SDAC and SDACA, respectively (Table 1). These results indicate a physisorption adsorption process.

\subsubsection{Temkin's Model}

The Temkin isotherm assumes that the heat of sorption of all the sorbates in the layer decreases linearly with coverage due to adsorbent-adsorbate interactions, and that the sorption process is characterized by a uniform distribution of binding energies, up to some maximum binding energy [26-28]. This model is expressed as Equations (14) and (15).

$$
\begin{gathered}
\mathrm{q}_{\mathrm{e}}=\beta \ln \mathrm{A}_{\mathrm{T}}+\beta \ln \mathrm{C}_{\mathrm{e}} \\
\beta=\mathrm{RT} \frac{1}{b}
\end{gathered}
$$

where $A_{T}$ is the constant $(\mathrm{L} / \mathrm{g})$ related to adsorbent/adsorbate binding; $\beta$ is a constant related to the heat of adsorption $(\mathrm{kJ} / \mathrm{mol})$; and $\mathrm{b}$ is the Temkin constant.

The AT and $\beta$ values were calculated from the slope and intercept of the Temkin plots (Figure 3). The estimated $\beta$ values of (SDAC) and (SDACA) were found for 9.9 and $12.6 \mathrm{~kJ} / \mathrm{mol}$ for SDAC and SDACA, respectively (Table 1). The estimated $\beta$ values were found to be $\leq 20 \mathrm{~kJ} / \mathrm{mol}$, indicating an adsorption process with a physisorption nature.

\subsection{Effect of Time and Kinetic Studies}

To study the effect of contact time on the sorption process, the sorption capacities of the SDAC and SDACA at different contact times were examined. Batch kinetics experiments were performed from 5 to 240 min under optimized conditions. $q_{t}$ and $q_{e}$ were calculated using Equations (3) and (4). Uranium ion removal initially increased rapidly within $5 \mathrm{~min}$, more slowly after that, and equilibrium was achieved within $180 \mathrm{~min}$ (Figure 4). Initially, this could be due to the availability of vacant binding sites (carboxylic and amino groups) to the surface of modified activated carbon within the first 5 min, the reaction of these functional groups with uranium ions decrease the vacant binding sites and hence the reaction become slower. The initial faster rate may be due to the higher ratio of the initial number of moles of metal ions to the available chelating sites. 

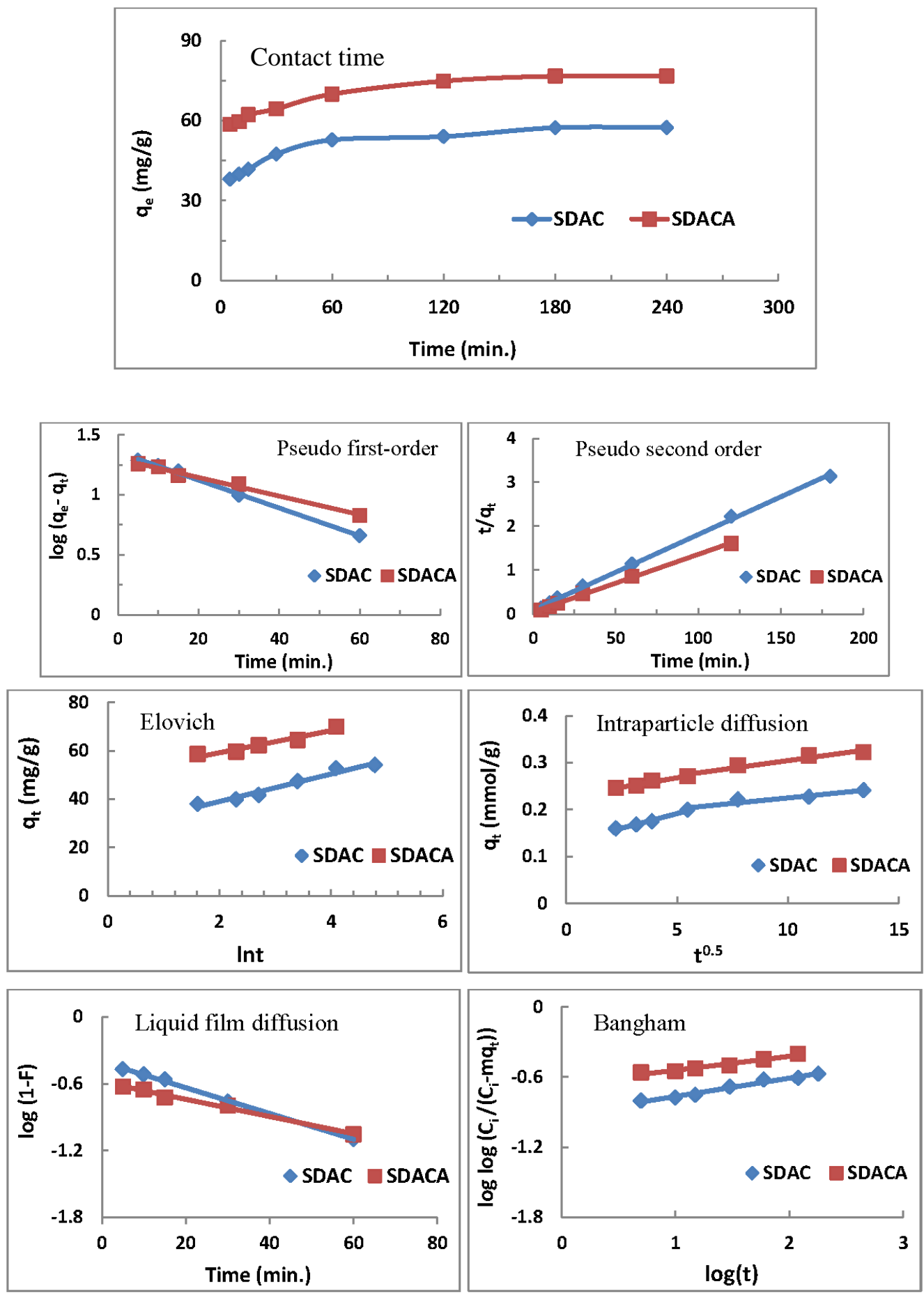

Figure 4. Effect of contact time, Pseudo first-order, pseudo Second-order, Elovich, Intraparticle diffusion, Liquid film diffusion and Bangham models for U(VI) adsorption by SDAC and SDACA.

The kinetic studies are of great importance for both gaining insights into the physical chemistry of the sorption processes and into the design of the sorption systems. In general, the sorption of uranium onto the SDAC and SDACA surface is known to proceed through the following steps; the diffusion of uranium across the external film surrounding the adsorbent beads (film diffusion); migration of uranium into pores, which is usually mentioned as pore diffusion; interaction of the radionuclide with available chelating sites on the interior surface of pores. The rate-limiting step results from one of the above steps or a combination of them. To gain insight into the sorption kinetics, the dataset time 
effect was used in the modeling exercise and the results obtained from several models are discussed below $[7,26-28]$.

\subsubsection{Pseudo-First-Order Model}

The Lagergren model assumes that the rate of uranium removal with time is directly proportional to the difference between the equilibrium capacity of adsorbents and the amount of uranium adsorbed at any time $\left(\mathrm{q}_{\mathrm{e}}-\mathrm{q}_{\mathrm{t}}\right)$. The pseudo-first-order model was used to investigate kinetic experimental data according to the linear form of the Lagergan equation (Equation (16)).

$$
\text { Pseudo - first order : } \log \left(\mathrm{q}_{\mathrm{e}}-\mathrm{q}_{\mathrm{t}}\right)=\log \left(\mathrm{q}_{1 \mathrm{st}}\right)-\frac{\mathrm{k}_{1}}{2.303} \mathrm{t}
$$

where $\mathrm{q}_{\mathrm{t}}$, is the experimental adsorption capacity at the time (t); and $\mathrm{q}_{1 \mathrm{st}}$ and $\mathrm{K}_{1}$ are the calculated adsorption capacity $(\mathrm{mg} / \mathrm{g})$ and the rate constant of pseudo-first-order models, respectively. Figure 4 shows the plots of $\log \left(\mathrm{q}_{\mathrm{e}}-\mathrm{q}_{\mathrm{t}}\right)$ vs. (t). The results reported in (Table 3 ) indicate the unsuitability of the Lagergren model to describe the adsorption process.

Table 3. Kinetic data for the adsorption of U(VI) ions by (SDAC) and (SDACA) adsorbents.

\begin{tabular}{|c|c|c|c|}
\hline Kinetic Model & Model Parameters & (SDAC) & (SDACA) \\
\hline \multirow{3}{*}{$\begin{array}{l}\text { Pseudo-first-order } \\
\text { kinetics }\end{array}$} & $\mathrm{q}_{1 \mathrm{st}},(\mathrm{mg} / \mathrm{g})$ & 22.6308 & 19.9388 \\
\hline & $\mathrm{k}_{1},\left(\min ^{-1}\right)$ & 0.0267 & 0.0177 \\
\hline & $R^{2}$ & 0.9984 & 0.9909 \\
\hline \multirow{3}{*}{$\begin{array}{l}\text { Pseudo-second-order } \\
\text { kinetics }\end{array}$} & $\mathrm{q}_{2 \mathrm{nd}},(\mathrm{mg} / \mathrm{g})$ & 58.1395 & 76.3358 \\
\hline & $\mathrm{K}_{2},(\mathrm{~g} /(\mathrm{mg} \cdot \mathrm{min}))$ & 0.0031 & 0.0038 \\
\hline & $\mathrm{R}^{2}$ & 0.9987 & 0.9986 \\
\hline \multirow{3}{*}{ Elovich kinetic model } & $\beta(\mathrm{g} / \mathrm{mg})$ & 0.1758 & 0.2191 \\
\hline & $\alpha(\mathrm{mg} /(\mathrm{g} \cdot \min ))$ & 744.2934 & $266,639.15$ \\
\hline & $\mathrm{R}^{2}$ & 0.9644 & 0.9387 \\
\hline \multirow{3}{*}{$\begin{array}{c}\text { Intraparticle diffusion } \\
\text { model }\end{array}$} & $\mathrm{K}_{\mathrm{ip}},\left(\mathrm{mg} /\left(\mathrm{g} \cdot \min ^{0.5}\right)\right)$ & 0.0047 & 0.0065 \\
\hline & I & 0.1778 & 0.2397 \\
\hline & $\mathrm{R}^{2}$ & 0.9109 & 0.9563 \\
\hline \multirow{2}{*}{$\begin{array}{l}\text { Liquid film diffusion } \\
\text { model }\end{array}$} & $\mathrm{K}_{\mathrm{fd}}$ & 0.0267 & 0.0177 \\
\hline & $\mathrm{R}^{2}$ & 0.9984 & 0.9909 \\
\hline \multirow{3}{*}{ Bangham kinetic model } & $\mathrm{K}_{\mathrm{b}}(\mathrm{mL} / \mathrm{g} / \mathrm{L})$ & 55.1345 & 100.5596 \\
\hline & $\mathrm{A}$ & 0.1556 & 0.119 \\
\hline & $\mathrm{R}^{2}$ & 0.9767 & 0.9595 \\
\hline
\end{tabular}

\subsubsection{Pseudo-Second-Order Model}

The pseudo-second-order model assumes that the sorption process is a pseudo-chemical reaction process [7]. In this model, the driving force is the difference between the equilibrium capacity of the adsorbent and the amount of uranium adsorbed at any time $\left(\mathrm{q}_{\mathrm{t}}\right)$, but the overall sorption rate is proportional to the square of the driving force. The pseudo-second-order sorption kinetic equation is expressed by Equation (20).

$$
\text { Pseudo - second order : } \frac{\mathrm{t}}{\mathrm{q}_{\mathrm{t}}}=\frac{1}{\mathrm{k}_{2} \mathrm{q}_{2 \mathrm{nd}}^{2}}+\frac{1}{\mathrm{q}_{\mathrm{e}}} \mathrm{t}
$$

where $\mathrm{q}_{2 \text { nd }}$ and $\mathrm{k}_{2}$ are the calculated adsorption capacity and the rate constant of pseudo-second-order models, respectively. Figure 4 shows the plots of $\left(t / q_{t}\right)$ vs. $(t)$. The results reported in (Table 3 ) indicated that the adsorption process followed the pseudo-second-order rather than pseudo-first-order kinetics. 


\subsubsection{Elovich Equation}

The Elovich model is useful when the reaction of uranium with the SDAC and SDACA active group is the rate-controlling step $[27,28]$. The model implies multilayer adsorption and assumes that the sorption sites increase exponentially with sorption (Equation (18)).

$$
\mathrm{q}_{\mathrm{t}}=\frac{1}{\beta} \ln (\alpha \beta)+\frac{1}{\beta} \ln (\mathrm{t})
$$

where $\beta$ and $\alpha$ are the adsorption constants $(\mathrm{g} / \mathrm{mg})$ and the initial adsorption rate $\left(\mathrm{mg} \cdot \mathrm{g}^{-1} \cdot \mathrm{min}^{-1}\right)$, respectively. The values of $\alpha$ and $\beta$ were obtained from the slope and intercept of plotting $q_{t}$ versus $\ln \mathrm{t}$, Figure 4, and reported in Table 3. The large difference between the calculated values $\alpha$ and the experimental $\mathrm{q}_{\mathrm{e}}$ indicates that the Elovich model does not describe the adsorption of uranium ions by SDAC and SDACA.

\subsubsection{Intra-particle Diffusion Model}

The intra-particle diffusion model (Weber-Morris model) assumes that the effect of the diffusion of uranium ions is the rate-controlling step in the sorption process, that the intra-particle diffusivity is constant, and the direction of the diffusion is radial [26-28]. This model was used to calculate the intra-particle diffusion rate constant. The model equation is given by Equation (19).

$$
\mathrm{q}_{\mathrm{t}}=\mathrm{K}_{\mathrm{ip}} \mathrm{t}^{0.5}+\mathrm{I}
$$

where $K_{i p}$ is the intraparticle diffusion rate constant and I is a constant proportional to the boundary layer $\left(\mathrm{mg} / \mathrm{g} \cdot \mathrm{min}^{0.5}\right)$. The larger the (I) value, the greater the contribution of the boundary layer [18]. The kinetic parameters for the Weber-Morris model were determined from the slope and intercept of the plots presented in Figure 4, and the results were recorded in Table 3. The smaller values of intra-particle diffusion $\left(\mathrm{K}_{\mathrm{ip}}\right)$ almost equal zero, and the higher values of the regression coefficient for the Weber-Morris model indicate that the intra-particle diffusion may be the rate-controlling step in the adsorption process.

\subsubsection{Liquid Film Diffusion Model}

During the transport of the solute species from the bulk liquid phase towards the solid adsorbent surface, the boundary layer may play a significant role in the adsorption process. This may be verified by applying the adsorption time data to the liquid film diffusion model $[25,28]$.

$$
\log (1-\mathrm{F})=-\frac{\mathrm{K}_{\mathrm{fd}}}{2.303} \mathrm{t}
$$

where $\mathrm{F}$ is the fractional attainment at equilibrium $\left(\mathrm{F}=\mathrm{q}_{\mathrm{t}} / \mathrm{q}_{\mathrm{e}}\right)$ and $\mathrm{K}_{\mathrm{fd}}$ is the film diffusion rate constant $\left(\mathrm{min}^{-1}\right)$. In case the plot of $\log (1-\mathrm{F})$ versus $(\mathrm{t})$ gives a straight line with a zero intercept, this indicates that the adsorption may be controlled by the diffusion through the liquid film at the adsorbent interface. Figure 4 shows the plot of $\log (1-F)$ versus $(t)$ for the adsorption time data of $\mathrm{U}(\mathrm{IV})$ ions onto SDAC and SDACA. The non-zero intercept, Table 3, indicates that the film diffusion is not the rate-determining step in the studied adsorption process.

\subsubsection{Bangham Model}

The Bangham model assumes that the diffusion of uranium into the pores of SDAC and SDACA beads is the rate-controlling step, Equation (21).

$$
\log \log \left(\frac{C_{i}}{C_{i}-m q_{t}}\right)=\log \left(\frac{m K_{b}}{2.303 V}\right)+\alpha \log t
$$


where $\mathrm{V}$ is the volume of solution $(\mathrm{mL}), \mathrm{m}$ is the weight of adsorbent per liter of solution $(\mathrm{g} / \mathrm{L})$, and $\alpha$ and $\mathrm{K}_{\mathrm{b}}(\mathrm{mL} / \mathrm{g} / \mathrm{L})$ are Bangham constants. The plots of the Bangham model, $\log \left(\mathrm{C}_{\mathrm{i}} /\left(\mathrm{C}_{\mathrm{i}}-\mathrm{mq}_{\mathrm{t}}\right) \mathrm{vs}\right.$. $\log (\mathrm{t})$ according are shown in Figure 4.

The straight lines obtained indicate that the pore diffusion may be the rate-determining step in the case of the two adsorbents (Table 3). The overall above results show that the pseudo-second-order, Bangham, and intra-particle diffusion models describe the adsorption process better than the other studied models.

As a conclusion of the kinetic studies, it was clear that the pseudo-second-order, Bangham, and intra-particle models were better at describing the adsorption process than the other studied models, and this was supported by the statistical indices obtained for each model.

\subsection{Effect of Adsorbent Dose}

Under the condition of a U(IV) concentration (100 ppm), operating temperature $\left(25^{\circ} \mathrm{C}\right)$ and adsorption solution $(25 \mathrm{~mL})$, the effect of the adsorbent dose (10-200 $\mathrm{mg}$ ) was examined. The results (Figure 5) indicated that the maximum uranium removal efficiencies were $89.72 \%$ for SDAC and $99.55 \%$ for SDACA of an adsorbent dose of $8 \mathrm{mg} / \mathrm{mL}$. That can be reasonably ascribed to the increasing of the adsorbing surface area and the greater availability of adsorption sites [24].

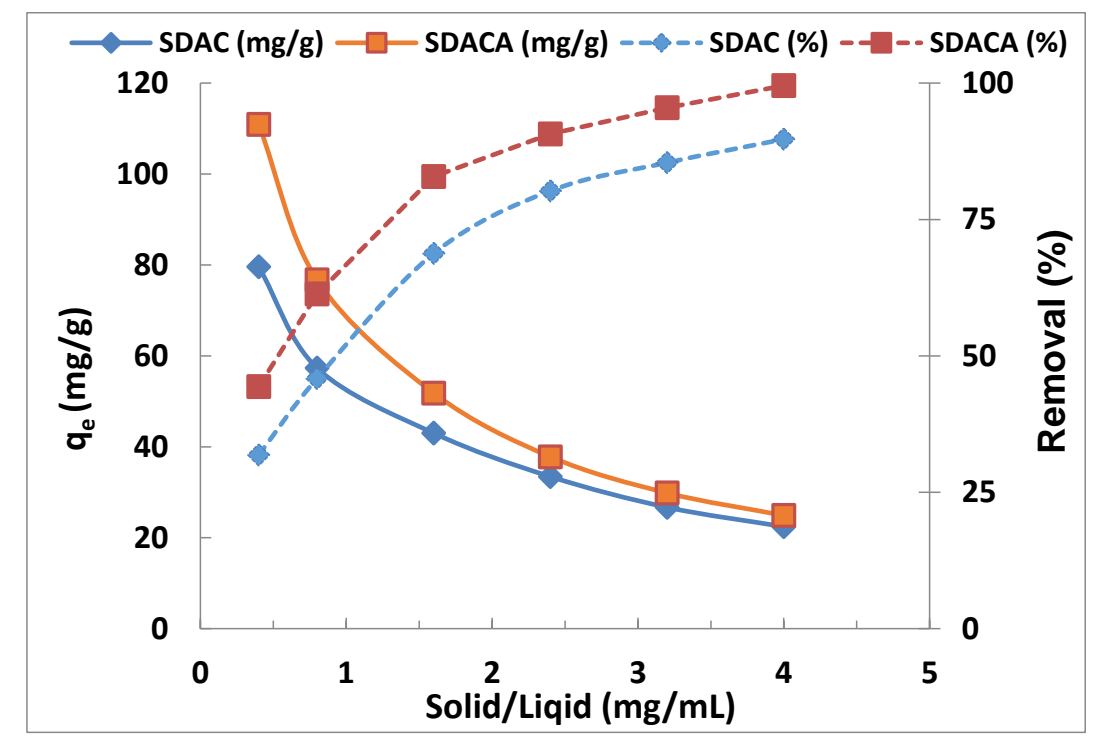

Figure 5. The effect of adsorbent dose on adsorption capacity and percentage removal.

\subsection{Adsorbent Regeneration}

Regeneration of use adsorbents provides several benefits such as cost-effectiveness, limited disposal costs, reduced environmental hazards and recovery of the loaded metals. Adsorbing and describing processes of uranium onto SDAC and SDACA were repeated several times. The SDAC and SDACA beads could be regenerated by washing with diluted $\mathrm{HNO}_{3}$. Also, acid contaminants were simply washed with alkaline water, after which the adsorbent became regenerated and ready for the next use. The regeneration efficiency (the ratio between the adsorption capacity of a given cycle and that of the previous one) was found to be $94-97 \%$ over three cycles with a standard deviation of $\pm 2.5 \%$.

\section{Application to Contaminated Groundwater}

Some of the water wells in the Wadi Naseib area, southwestern Sinai, Egypt recorded higher concentrations of uranium and other heavy metals than the permissible levels that impose serious effects on human health. The source of these elements usually comes from the surrounding rocks 
under the rain effect. The chemical analysis of the treated water samples (Table 4) showed, in addition to the uranium, high concentrations of some anions and cations which may reflect the effect of the surrounding rock composition (silt-stone, Dolostone, and Black shale) $[29,30]$.

Table 4. Chemical analysis of the groundwater sample.

\begin{tabular}{cccc}
\hline Constituents & $\begin{array}{c}\text { Concentration, } \\
\mathbf{m g} / \mathrm{L}\end{array}$ & Constituents & $\begin{array}{c}\text { Concentration, } \\
\mathbf{m g} / \mathbf{L}\end{array}$ \\
\hline $\mathrm{pH}$ & 7.2 & $\mathrm{U}$ & 1.8 \\
$\mathrm{TDS}$ & 2810 & $\mathrm{Cu}$ & 0.018 \\
$\mathrm{Ca}^{2+}$ & 343 & $\mathrm{Co}$ & 0.022 \\
$\mathrm{Mg}^{2+}$ & 277 & $\mathrm{Cr}$ & 0.004 \\
$\mathrm{Na}^{+}$ & 314 & $\mathrm{As}$ & 0.057 \\
$\mathrm{~K}^{+}$ & 35 & $\mathrm{Zr}$ & 0.036 \\
$\mathrm{SO}_{4}^{2-}$ & 452 & $\mathrm{Cd}$ & 0.008 \\
$\mathrm{CO}_{3}^{2-}$ & 510 & $\mathrm{~Pb}$ & 0.091 \\
$\mathrm{Cl}^{-}$ & 370 & $\mathrm{Fe}$ & 2.067 \\
\hline
\end{tabular}

Both SDAC and SDAC were employed to remove the uranium from this water. Water sample analysis were achieved by inductively coupled plasma-mass spectrometry (ICP-MS, Joel Brand, JMS-PLASMAX2), and the uranium adsorption from the contaminated groundwater was carried out under the obtained optimum conditions and the results (Table 5) showed high removal efficiency values, indicating the validity of the prepared activated carbons for treatment of contaminated water bodies.

Table 5. Results of treatment of groundwater samples with SDAC and SDACA adsorbents.

\begin{tabular}{ccccc}
\hline Adsorbents & Elements & $\begin{array}{c}\text { Permissible } \\
\text { Levels }(\mathbf{m g} / \mathrm{L})\end{array}$ & Well-1 & Well-2 \\
\hline \multirow{5}{*}{ SDAC } & $\mathrm{U}$ & $0.03-0.015$ & 0.01 & 0.006 \\
& $\mathrm{Ni}$ & 0.1 & 0.09 & - \\
$\mathrm{Cu}$ & 1.0 & 0.005 & - \\
& $\mathrm{Co}$ & 0.002 & 0.003 & - \\
& $\mathrm{Cr}$ & 0.1 & - & 0.004 \\
& $\mathrm{As}$ & 0.01 & - & - \\
$\mathrm{Cd}$ & 0.005 & - & - \\
& $\mathrm{Pb}$ & 0.015 & 0.30 & - \\
$\mathrm{Fe}$ & 0.3 & - & - \\
& $\mathrm{F}$ & $0.03-0.015$ & - & - \\
& $\mathrm{Ni}$ & 0.1 & - & - \\
$\mathrm{Cu}$ & 1.0 & - & - \\
& $\mathrm{Co}$ & 0.002 & - & - \\
& $\mathrm{Cr}$ & 0.1 & - & - \\
& $\mathrm{As}$ & 0.01 & - & - \\
\hline $\mathrm{Cd}$ & 0.005 & 0.04 & - \\
\hline
\end{tabular}

\section{Conclusions}

The present work demonstrates that SDAC and SDACA have a high sorption capacity for uranium and can be successively used for the fast removal of $\mathrm{U}(\mathrm{VI})$ ions from aqueous solutions. On the one hand, the monolayer sorption was the favored mechanism for both the used adsorbents. On the other hand, the sorption process revealed its endothermic nature. Finally, this study verified amino-activated carbon as a highly efficient and low-cost adsorbent that can be widely used in the treatment of polluted water systems, for either radioactive elements or some heavy metals. 
Author Contributions: M.O. Abd El-Magied and M.A. Mahmoud conceived, designed and performed the experiments, analyzed the data, created the Figures, and wrote the manuscript. T.F. Mohammaden, I.K. El-Aassy, A.M. Hassan and H.M.H. Gad contributed reagents/materials/analysis tools, supervised the work and helped with interpreting the data.

Conflicts of Interest: The authors declare no conflict of interest.

\section{References}

1. Sincero, S.A.P.; Sincero, G.A. Physical-Chemical Treatment of Water and Wastewater; CRC Press: Boca Raton, FL, USA, 2003.

2. Cheremisinoff, N.P. Handbook of Water and Wastewater Treatment Technologies; Butterworth-Heinemann: Oxford, UK, 2002.

3. Ahuja, S. Handbook of Water Purity and Quality, 1st ed.; Elsevier Inc.: Amsterdam, The Netherlands, 2009.

4. Sadeek, A.S.; Moussa, E.M.M.; El-Sayed, M.A.; Amine, M.M.; Abd El-Magied, M.O. Uranium(VI) and Thorium(IV) adsorption Studies on Chelating Resin Containing Pentaethylenehexamine as a Functional Group. J. Disper. Sci. Technol. 2014, 35, 926-933. [CrossRef]

5. Merkel, B.J.; Friedrich, B.P. Groundwater Geochemistry; Springer: Berlin/Heidelberg, Germany, 2002.

6. Cotton, F.A.; Wilkinson, G.; Murillo, C.A.; Bochmann, M. Advanced Inorganic Chemistry; John Wiley \& Sons: Hoboken, NJ, USA, 1980.

7. Donia, A.M.; Atia, A.A.; Moussa, E.M.M.; El-Sherif, A.M.; Abd El-Magied, M.O. Removal of Uranium(VI) from aqueous solutions using glycidyl methacrylate chelating adsorbents. Hydrometallurgy 2009, 95, 183-189. [CrossRef]

8. Katsoyiannis, I.A.; Zouboulis, A.I. Removal of uranium from contaminated drinking water: A mini review of available treatment methods. Desalin. Water Treat. 2013, 51, 2915-2925. [CrossRef]

9. Katsoyiannis, I.A.; Althoff, H.W.; Bartel, H.; Jekel, M. The effect of groundwater composition on uranium(VI) sorption onto bacteriogenic iron oxides. Water Res. 2006, 40, 3646-3652. [CrossRef] [PubMed]

10. Yang, A.; Yang, P.; Huang, C.P. Preparation of graphene oxide-chitosan composite and adsorption performance for uranium. J. Radioanal. Nucl. Chem. 2017, 313, 371-378. [CrossRef]

11. Chmielewska, E.; Tylus, W. Adsorption of $\mathrm{Al}(\mathrm{III}), \mathrm{Sb}(\mathrm{III})$, chromate and halides onto some natural versus commercial materials. J. Radioanal. Nucl. Chem. 2016, 308, 887-893. [CrossRef]

12. Petrov, V.G.; Kuchinskaya, T.S.; Perfiliev, Y.D.; Dedushenko, S.K.; Kalmykov, S.N. Radionuclide removal from aqueous solutions using potassium ferrate(VI). J. Radioanal. Nucl. Chem. 2016, 310, 347-352. [CrossRef]

13. Yi, Z.; Yuan, Z.; Yao, J.; Liu, X.; Zhu, M.J.; Chen, H.L.; Wang, F. Batch study of uranium biosorption by Elodea canadensis biomass. J. Radioanal. Nucl. Chem. 2016, 310, 505-513. [CrossRef]

14. Peng, X.; Li, Y.; Ma, J.; Cui, Y.; Sun, G. Extraction and separation of uranium(VI) and Fe(III) from lanthanide chlorides with $\mathrm{N}, \mathrm{N}, \mathrm{N}, \mathrm{N}$-tetra substituted alkyl diglycolamide extractants. J. Radioanal. Nucl. Chem. 2017, 313, 327-332. [CrossRef]

15. Yakout, S.M.; Metwally, S.S.; El-Zakla, T. Uranium sorption onto activated carbon prepared from rice straw: Competition with humic acids. Appl. Surface Sci. 2013, 280, 745-750. [CrossRef]

16. Taskaev, E.; Apostolov, D. On uranium(VI) adsorption on activated carbon. J. Radio Anal. Chem. 1978, 45, 65-71. [CrossRef]

17. Ahmed, S.H.; Sharaby, C.M.; El Gammal, E.M. Uranium extraction from sulfuric acid medium using trioctylamine impregnated activated carbon. Hydrometallurgy 2013, 134-135, 150-157. [CrossRef]

18. Rodriguez, R.V.; Cabrera, M.E.M.; Ponce, H.E.E.; Peraza, E.F.H.; Casarrubias, M.L.B. Uranium removal from water using cellulose triacetate membranes added with activated carbon. Appl. Radiat. Isot. 2012, 70, 872-881. [CrossRef] [PubMed]

19. Afsari, M.; Safdari, J.; Towfighi, J.; Mallah, M.H. The adsorption characteristics of uranium hexafluoride onto activated carbon in vacuum conditions. Ann. Nucl. Energy 2012, 46, 144-151. [CrossRef]

20. Saleha, T.A.; Naeemullahb; Tuzenb, M.; Sarı, A. Polyethylenimine modified activated carbon as novel magnetic adsorbent for the removal of uranium from aqueous solution. Chem. Eng. Res. Des. 2017, 117, 218-227. [CrossRef] 
21. Gad, H.M.H.; Mohammaden, T.F.; Mahmoud, M.A. Solid phase extractive pre-concentration of uranium(VI) from liquid waste onto peach stone steam pyrolysis activated carbon. Asian J. Chem. 2013, 28, 751-760. [CrossRef]

22. Zhu, M.; Yi, Z.; Liu, R.; Chai, H.; Yao, J.; Chen, Y. Hazelnut shell activated carbon: A potential adsorbent material for the decontamination of uranium(VI) from aqueous solutions. J. Radioanal. Nucl. Chem. 2016, 310, 1147-1154. [CrossRef]

23. Zheng, Z.; Cao, X.; Zhang, Z.; Wang, Y.; Dai, Y.; Liu, Y.; Zhao, W.; Le, Z.; Xiong, G.; Yu, S. Adsorptive removal of uranyl ions in aqueous solution using hydrothermal carbon spheres functionalized with 4-aminoacetophenone oxime group. J. Radioanal. Nucl. Chem. 2017, 312, 187-198. [CrossRef]

24. Menacer, S.; Lounis, A.; Guedioura, B.; Bayou, N. Uranium removal from aqueous solutions by adsorption on Aleppo pine sawdust, modified by $\mathrm{NaOH}$ and neutron irradiation. Desalin. Water Treat. 2015, 57, 1-12. [CrossRef]

25. Sadeek, A.S.; El-Sayed, M.A.; Amine, M.M.; Abd, E.L.; Magied, M.O. A chelating resin containing trihydroxybenzoic acid as the functional group; synthesis and adsorption behavior for Th(IV) and U(VI) ions. J. Radioanal. Nucl. Chem. 2014, 299, 1299-1306. [CrossRef]

26. Abd El-Magied, M.O.; Tolba, A.A.; El-Gendy, H.S.; Zaki, S.A.; Atia, A.A. Studies on the recovery of Th(IV) ions from nitric acid solutions using amino-magnetic glycidyl methacrylate adsorbents and application to granite leach liquors. Hydrometallurgy 2017, 169, 89-98. [CrossRef]

27. Abd El-Magied, M.O. Sorption of uranium ions from their aqueous solution by adsorbents containing nanomagnetite particles. J. Eng. 2016, 2016, 7214348. [CrossRef]

28. Abd El-Magied, M.O.; Elshehy, E.A.; Manaa, E.A.; Tolba, A.A.; Atia, A.A. Kinetics and thermodynamics studies on the recovery of thorium ions using amino adsorbents with magnetic properties. Ind. Eng. Chem. Res. 2016, 55, 11338-11345. [CrossRef]

29. El Nagdy, M.S.; Ali, B.H.; El Wakil, A.F.; Gaber, K.A. Effect of physical parameters in measuring some poisonous and radionuclides in groundwater using ICP-OES: A case study in Southwestern Sinai, Egypt. Arab J. Nucl. Sci. Appl. 2016, 94, 74-84.

30. Hamza, M.F.; El Aassy, I.E. Solid phase extraction of uranium removal from underground water, Wadi Naseib, Southwestern Sinai, Egypt. Desalin. Water Treat. 2014, 52, 331-338. [CrossRef] 